\title{
FINANCIAMENTO DA EDUCAÇÃO BÁSICA NO BRASIL: Algumas reflexões
}

Daniela Dermínio Posterare Santos

Horácio Rosa Vieira

\section{RESUMO}

O presente estudo busca analisar as transformações que ocorreram na história da legislação brasileira referentes ao financiamento da educação básica no Brasil, a forma com que, ao longo do tempo, os percentuais de investimentos em educação foram utilizados, as origens dos fundos e destinações percentuais, a criação do Fundo Nacional de Desenvolvimento da Educação Básica - FUNDEB, bem como os valores necessários para promover a qualidade na educação básica. Há reflexões sobre a utilização dos $10 \%$ do Produto Interno Bruto - PIB, sobre quais os fatores que interferem para a elevação do nível da educação no Brasil e apontamentos demonstrando que maiores recursos tendem a colaborar para que a educação básica brasileira alcance melhores índices. A participação da sociedade civil, principalmente dos pais, professores e gestores é requisito para uma correta aplicabilidade do fundo, assim como debates públicos e conferências que discutam soluções para a formação cidadã e equidade no processo de ensinoaprendizagem. A valorização dos profissionais da educação, com plano de carreira e estrutura adequada de trabalho, também contribui ao progresso educacional.

Palavras-chave: Educação Básica. Financiamento. Fundo Nacional de Desenvolvimento da Educação no Brasil. Qualidade educacional. Valorização.

\section{INTRODUÇÃO}

No período do Brasil Colônia, em 1551, os jesuítas foram responsabilizados, pelo Estado, pela educação formal pública no país e os representantes da Companhia de Jesus eram os responsáveis pelas escolas, até meados do século XVIII, quando os jesuítas foram expulsos e o governo de Portugal ficou responsável pela educação no Brasil, atendendo menos de 5\% da população em idade escolar. Nesta época, a educação era custeada por meio de um novo tributo que os próprios brasileiros contribuíam, o "Subsídio Literário" (BRASIL, 2006; CALLEGARI, 2008). 
Segundo Callegari (2008, p. 31), a partir da movimentação obtida por meio do Manifesto dos Pioneiros da Educação, que propunha uma educação “... de grande alcance e de vastas proporções... um plano com sentido unitário e com base científica”, em 1932, foi promulgado o artigo 150 da Constituição Brasileira de 1934, que declarava ser competência da União a fixação de um plano nacional de educação que abarcasse todos os graus e modalidades de ensino, bem como coordenasse e fiscalizasse sua execução. Neste artigo ficou estabelecido que a União destinaria $10 \%$ de seus impostos para a educação, os Estados e o Distrito Federal 20\% e para o ensino das zonas rurais a União destinaria $20 \%$ das cotas anuais de educação.

Em 1946, na Carta Magna, ficou estabelecido que a União aplicaria, anualmente, nunca menos de 10\%, os Estados, o Distrito Federal e os Municípios nunca menos de $20 \%$ da renda resultante dos impostos na manutenção e desenvolvimento do ensino (BRASIL, 2006).

As porcentagens sofreram modificação com a Lei de Diretrizes e Bases de 1961 (LDB - Lei 4.024/61), que previa que a União aplicaria 12\%, enquanto os Estados, o Distrito Federal e os municípios 20\%, no mínimo, de sua receita de impostos. A Lei estabelecia ainda que os Estados, o Distrito Federal e os municípios que deixassem de aplicar a porcentagem prevista na Constituição não poderiam solicitar auxílio da União para esse fim (BRASIL, 1996).

Assim, ficou evidente a tentativa de fortalecer os órgãos vinculados à educação e, posteriormente, foi elaborado o Plano de Educação para o período de 1962 a 1970. Nesta época houve concentração de poder na União, resultado do militarismo em 1964, ocasionando o enfraquecimento dos governos estaduais e municipais nas decisões. Foi adotado o modelo institucional pelo Governo de 1964, com foco na centralização, burocracia e autoritarismo. Esse modelo foi reproduzido pelas secretarias e órgãos da educação de estados e municípios, contribuindo para a ineficiência da gestão educacional do país.

A educação era entendida como meio de desenvolvimento para o país no Brasil República e então houve o surgimento de ideias para um Plano Nacional. A preocupação que havia era em todos os níveis da educação, diversas reformas auxiliaram a entender a educação como assunto coletivo e um problema nacional (CALLEGARI, 2008).

Em 1964, pela Lei 4.440, criou-se outra fonte importante de financiamento, o "salárioeducação", destinado somente ao ensino fundamental público (PINTO e ADRIÃO, 2006). 
Callegari (2008) afirma que, na Emenda Constitucional de 1969, a vinculação de recursos ficou limitada aos municípios e a União, que já vinha descumprindo o dispositivo da antiga LDB, ficou liberada de qualquer obrigação. Essa desvinculação de recursos foi desastrosa para a educação.

Na década de 1970, com a crise do petróleo, a era do milagre econômico acabou e contribuiu para que o planejamento se tornasse um instrumento burocrático e técnico, servindo como mecanismo de controle para repasse de verbas.

Iniciou-se, então, um período de lutas pela volta da vinculação constitucional, liderada pelo senador João Calmon. Em 1983, foi aprovada a Emenda Calmon, que previa a aplicação de $13 \%$ pela União e $20 \%$ pelos Estados, Distrito Federal e Municípios da receita proveniente de impostos na manutenção e desenvolvimento do ensino (CALLEGARI, 2008).

A Constituição Federal de 1988 e a Lei de Diretrizes e Bases de 1996 dividem as competências e responsabilidades entre a União, os Estados e os Municípios, o que também se aplica ao financiamento e manutenção dos diferentes níveis da educação e do ensino (BRASIL, 1996).

No entanto, essa forma de organização não indica, necessariamente, que o sistema educacional brasileiro seja plenamente descentralizado. A descentralização da gestão vem se constituindo em um grande desafio visando a consolidação da dinâmica federativa do Estado brasileiro e à democratização do poder e dos processos decisórios nas suas diferentes estruturas organizacionais (MEC, 2006).

Na Constituição de 1988 ficou estabelecido que a União aplicaria, na manutenção e desenvolvimento do ensino, no mínimo, 18\%, os Estados, o DF e os municípios 25\% da receita resultante de impostos, incluindo a proveniente de transferências (BRASIL, 1988).

Com a reforma tributária de 1988, responsável pela determinação de que não seria permitido financiar programas suplementares de alimentação e saúde escolar, houve a ausência de recursos. Por isso, o Estado não conseguiu arcar com as despesas para manter a própria rede, o que foi um impulso à municipalização do ensino Fundamental, pois assim, aliviaria a manutenção deste nível de ensino (DAVIES, 2006).

De acordo com Callegari (2008), após oito anos da Constituição de 1988, em 1996, a taxa de escolarização era de 90,8\%, faltando cerca de três milhões de matrículas em relação à almejada universalização do ensino fundamental em idade própria. 
Em 1996 foi criado o FUNDEF - Fundo de Manutenção e Desenvolvimento do Ensino Fundamental (Lei 9.424, de 24 de dezembro de 1996) no âmbito dos Estados e do Distrito Federal, constituído de $15 \%$ das receitas provenientes de impostos e transferências, para distribuição entre o Estado e seus municípios, proporcionalmente às matrículas no ensino Fundamental, focando na municipalização do ensino fundamental (BRASIL, 1996).

O Fundo Nacional de Desenvolvimento do Ensino Fundamental - FUNDEF foi responsável pela redistribuição da receita arrecadada pelos municípios e estados de alguns impostos (Imposto sobre Circulação de Mercadorias e Serviços - ICMS, Fundo de Participação dos Municípios - FPM, Fundo de Participação dos Estados - FPE, Imposto dobre Produtos Industrializados, proporcional as exportações - IPI exportação) para o desenvolvimento do ensino fundamental (MEC, 2006).

No entanto, esse fundo não trouxe grande novidade, cuidou apenas para a distribuição igualitária de $15 \%$ dos recursos arrecadados distribuídos por número de alunos matriculados no ensino fundamental. Esse fundo vigorou de 1998 a 2006, era um fundo de subvinculação das receitas da educação, dos $25 \%$ da receita vinculada, $60 \%$ era destinado ao ensino fundamental. (DAVIES, 2006).

Segundo Davies (2006), o FUNDEF foi um mecanismo indutor da descentralização, a expectativa era de que os municípios optassem por assumir matrículas do Ensino Fundamental para não abrirem mão de parcela de suas receitas, ou seja, como consequência foi induzida a municipalização e, houve dificuldades financeiras para a educação infantil, para o ensino médio e também para a educação de jovens e adultos.

Callegari (2008) afirma que, nesse tempo, houve um avanço no atendimento do ensino fundamental, pouco faltando para a sua universalização. Porém, em termos qualitativos, dados do Sistema de Avaliação da Educação Básica - SAEB - de 1995 a 2005, mostram decadência no rendimento dos alunos. Com relação à erradicação do analfabetismo, poucos avanços aconteceram. Em 1996 eram 16 milhões de analfabetos com idade de 15 anos ou mais e em 2005 eram quase 15 milhões.

Após o período que vigorou o FUNDEF - de 1997 a 31 de dezembro de 2006, o Fundo Nacional de Desenvolvimento da Educação Básica - FUNDEB substituiu o FUNDEF, com poucas modificações. Uma das mudanças desse fundo era que $20 \%$ dos recursos eram distribuídos proporcionalmente pelo número de matrículas no ensino básico, ou seja, desde a educação infantil até o ensino médio, e não somente no ensino fundamental, como no FUNDEF. Outra pequena mudança foi a ampliação dos impostos 
para compor esse fundo. Além dos impostos já citados que compunham o FUNDEF, acrescentou-se o Imposto sobre Transmissão Causa Mortis e Doação - ITCMD, Imposto sobre Propriedade de Veículos Automotores - IPVA, Imposto sobre Renda e Proventos incidentes sobre rendimentos pagos pelos municípios, Imposto sobre Renda e Proventos incidentes sobre rendimentos pagos pelos estados, cotaparte de 50\% do Imposto Territorial Rural - ITR devida aos municípios (MEC, 2006).

O período de duração do FUNDEB é de 14 anos, com implantação gradativa, objetivando ampliar os investimentos anuais, inclusive os provenientes da União, responsável por complementar os recursos quando o valor anual por aluno, nos Estados e no Distrito Federal, não alcançar o mínimo definido nacionalmente. $\mathrm{O}$ valor a ser repassado pela União considerará os valores mínimos diferenciados para cada etapa e modalidade de ensino da educação básica.

Esse fundo, de natureza contábil e de âmbito estadual (um fundo por estado e Distrito Federal, num total de vinte e sete fundos), é formado por recursos provenientes dos impostos e transferências dos Estados, Distrito Federal e Municípios, vinculados à educação (CALLEGARI, 2008).

Além desses recursos, ainda compõe o FUNDEB, a título de complementação, uma parcela de recursos federais, sempre que, no âmbito de cada Estado, seu valor por aluno não alcançar o mínimo definido nacionalmente. Independente da origem, todo o recurso gerado é redistribuído para aplicação exclusiva na educação básica (DAVIES, 2006).

Os recursos do FUNDEB de cada estado são repartidos na proporção do número de alunos matriculados na educação básica das redes de ensino estaduais e municipais. Em cada Estado, proporcionalmente às respectivas matrículas (obtidas pelo Censo Escolar), o Estado e seus municípios tornam-se beneficiários dos recursos distribuídos pelo FUNDEB (BRASIL, 2007).

Além dos fundos mencionados, o governo federal também financia programas nacionais para as escolas públicas de educação básica, tais como:

- Programa Dinheiro Direto na Escola - PDDE

- Programa Nacional de Alimentação Escolar - PNAE

- Programa Nacional de Apoio ao Transporte Escolar - PNATE

- Programa Nacional Biblioteca da Escola - PNBE

- Programa Nacional de Saúde no Escolar - PNSE

- Programa Nacional do Livro Didático - PNLD 
Esses programas têm por objetivo prover as escolas públicas de educação básica das redes federal, estadual e municipal de recursos que ampliem as possibilidades e auxiliem no desenvolvimento das atividades educativas previstas.

As fontes de recursos para os programas não são padronizadas, o Programa Nacional da Biblioteca Escolar - PNBE, por exemplo, é financiado com recursos consignados no orçamento do Fundo Nacional de Desenvolvimento da Educação FNDE, enquanto o Programa Nacional do Livro Didático é financiado com recursos provenientes de dotações consignadas no orçamento do Ministério da Educação.

Percebe-se, então, um alto investimento por parte do governo federal na educação básica brasileira.

\section{REFLEXÕES SOBRE O FINANCIAMENTO DA EDUCAÇÃO BÁSICA NO BRASIL}

O FUNDEB, assim como o FUNDEF, trouxeram poucos recursos novos para o sistema educacional como um todo, já que o objetivo desses dois fundos é a distribuição dos recursos que já são constitucionalmente vinculados à educação, entre os estados e os municípios tendo como base o número de matrículas na educação básica, no caso do FUNDEB. Isso significa que alguns municípios ganharão ou perderão na mesma proporção, principalmente quando não houver complementação pela União. Muitos municípios com população menor e com receita própria acabam sendo prejudicados com o FUNDEB (DAVIES, 2006).

Davies (2006) destaca ainda que o FUNDEB exclui a educação profissional que, embora, segundo a LDB e o Censo do INEP, também faz parte da educação básica.

Sobre os recursos destinados à educação básica e a necessidade de ampliação do investimento para uma maior equidade, reflete-se que a educação precisa de mais recursos do que está recebendo, ou então, uma distribuição mais adequada, de acordo com necessidades regionais, para que a qualidade educacional possa ser garantida.

Atualmente, tem-se discutido, em vários âmbitos, uma política de crescente elevação e a ampliação do financiamento na educação. Essas discussões provocam a participação de vários setores, principalmente dos mais envolvidos e diretamente necessitados. Essa voz ativa representa, não apenas uma categoria em busca de melhores condições de trabalho, mas, o cuidado com um setor de fundamental importância para a 
edificação da melhoria da qualidade na educação e sua universalização, consequentemente.

Cruz (2009) aponta alguns problemas referentes à política de financiamento da educação no Brasil

... os recursos são insuficientes; 2) a política macroeconômica tem influenciado diretamente a política educacional, de forma a minimizar os recursos destinados à educação; 3) persistem práticas como desvios de finalidades, sonegações e isenções, que fragilizam a oferta educacional pública; 4) a má administração dos parcos montantes destinados à educação ainda é uma realidade, problema acentuado pelo frágil controle social existente; 5) as políticas implementadas resultam em conflitos de responsabilidades, que favorecem a desresponsabilização por parte dos entes federados, especialmente da União, que não cumpre sua função supletiva e redistributiva em relação aos estados e municípios, como previsto constitucionalmente (CRUZ, 2009, p. 12).

Países com altos índices nos rankings enfrentaram também inúmeros problemas como estes e como formas para solucionar os impasses buscaram na valorização e formação do professor, um plano de carreira que estimula jovens à prática pedagógica com a oferta de uma carreira com claro resultado em metas e objetivos a serem alcançados, recursos tecnológicos e infraestrutura adequada. Para DAVIES (2006) não se vislumbra em curto prazo nas políticas atuais uma real melhoria na política salarial do professor. Outro fator importante é a formação e a carga horária de trabalho. Há, em alguns estados, programas de formação com o objetivo de atender às várias demandas educacionais, porém, em outros estados, a precariedade é enorme, seja na jornada de trabalho extensa e extenuante, não possibilitando momentos para formação contínua, ou mesmo jornadas triplas para o aumento da renda, ou ainda por falta de profissionais qualificados, pois são contratados professores ainda em formação e sem experiência (que pode ser iniciada ao final da graduação, por meio de estágios) para atender a uma demanda urgente.

Assim, fica evidente a necessidade de maior investimento na valorização dos profissionais da educação. Não se trata de melhorar apenas o salário, mas também a criação de um plano de carreira que abranja formação contínua, para que haja progressos na prática profissional e, consequentemente, a superação dos índices atuais. 
Um requisito fundamental para a melhoria educacional será alcançar um referencial de qualidade, porém, deve este fazer equivalência aos índices oficiais mundiais, ou ter uma participação coletiva de gestores, escola, comunidade e pais que, de acordo com as necessidades reais, possam traçar objetivos pensando em critérios como igualdade, justiça e respeito às diferenças.

Melhorar a relação ensino e aprendizagem com os recursos financeiros destinados a tal fim é obrigação da federação, que divide responsabilidade com estados e municípios na arrecadação e distribuição de recursos. A melhoria dos índices educacionais reflete, sobretudo, no âmbito social do país, com o poder de compra, aumento da criticidade e participação política.

O planejamento da parte pedagógica e financeira deve ser cuidadosamente realizado, com a participação de todas as camadas sociais e dos profissionais especialistas. Um modelo geral é pertinente e, além disso, é necessário que tenha profissionais capacitados e que todos os envolvidos analisem e opinem sobre as decisões, levando em consideração as características de cada unidade e seus anseios, direcionando os recursos de forma a atender às demandas de cada local.

O maior investimento deverá ocorrer na base da educação, ou seja, nas creches, já que o início da formação é fundamental e reflete no prosseguimento dos estudos. Feita uma distribuição adequada dos recursos, que considere as necessidades individuais, certamente haverá diminuição de desigualdades em virtude de maior arrecadação e maior repasse. Isso sim seria uma política pública visando o bem estar da população em um setor prioritário como a educação.

No Brasil, que possui um tamanho continental, há inúmeros problemas ainda nos diversos segmentos da educação, principalmente de acesso nos anos iniciais. Portanto, é pertinente a discussão sobre qualidade, pensar na universalização do acesso, para que todos sejam atendidos, e no meio do processo, melhorar o nível educacional.

Movimentos como a Conferência Nacional de Educação - Conae - possibilitam o debate público de todos os segmentos envolvidos com a educação e seu caráter democrático traz a prerrogativa da equidade e participação popular, inclusive das camadas mais carentes.

Ramos e Di Giorgi (2011) afirmam que uma gestão democrática pode ser responsável por uma distribuição igualitária de fundos e, com o FUNDEB, isso se potencializa, por haver transparência na gestão pública e maior participação popular. 
Com um valor adequado o aluno da rede pública pode ter igualdade de condições ao da rede particular, equiparando promove-se a paridade, o que legitima um projeto político-democrático adequado a uma das maiores economias do mundo e com índices baixíssimos de educação, afinal, os recursos estão disponíveis e devem atender a todos, bem como serem ampliados, como se solicita há anos o uso dos $10 \%$ do PIB para a educação.

Winckler (2007) afirma que se deve analisar a aplicação dos recursos para que ocorra uma distribuição equitativa e não apenas um novo formato de financiamento sem alterar a realidade das desigualdades regionais.

O Fundeb segue, em linhas gerais, a lógica do Fundef. Sua abrangência foi ampliada ao conjunto da educação básica, incorporando a educação de jovens e adultos, redistribuindo e abarcando novas fontes de recursos, sem alterar os percentuais obrigatórios de investimento na educação, estabelecidos constitucionalmente para os entes federados. Persiste, na lógica do Fundeb, a possibilidade de reprodução das desigualdades regionais, pois serão mantidos 27 fundos regionais (WINCKLER, 2007, p. 9).

\section{CONSIDERAÇÕES FINAIS}

Concluindo, refletimos sobre a íntima relação da garantia da educação como um direito com o financiamento por parte do poder público, que acontece por meio da arrecadação de impostos. Entender o financiamento, bem como as fases que a educação básica formal passou no Brasil, revela as conquistas e as defasagens do nosso sistema educacional brasileiro.

Podemos dizer que o maior problema na educação está no investimento financeiro, pois, para promover qualidade é necessária a injeção de recursos, embora saibamos que há uma grande quantidade de impostos e a arrecadação corresponde a uma das maiores economias do mundo.

No entanto, sugerimos que um dos problemas esteja na má distribuição dos recursos e, cabe à população, através de uma participação ativa, reivindicar seus direitos para um futuro melhor, participando das discussões e fiscalizando os gastos com a educação, ao contrário de aceitar passivamente ordenações quer não promovam melhorias. 
Sugerimos, também, que a valorização dos profissionais da educação seja tida como umas das prioridades na aplicação dos fundos, pois eles são os principais responsáveis pelo desenvolvimento educacional de cidadãos brasileiros, preparando-os para um mundo globalizado. Essa valorização deveria abarcar recursos didáticos e pedagógicos, infraestrutura física e tecnológica, salários justos, formação continuada, entre outros quesitos importantes no desenvolvimento da educação pública formal no país.

\section{REFERÊNCIAS BIBLIOGRÁFICAS}

BRASIL. Conselho Escolar e o Financiamento da Educação no Brasil. Ministério da Educação. Brasília - DF, jun. 2006.

BRASIL. Constituição da República Federativa do Brasil de 1988. Brasília: Senado Federal. Disponível em: www.plananlto.gov.br. Acesso em: ago. 2013.

BRASIL. Lei 9.394, de 20/12/96. Estabelece as diretrizes e bases da educação nacional. Brasília: Presidência da República. Disponível em: www.planalto.gov.br. Acesso em: ago. 2013.

BRASIL. Lei 11.494, de 20/06/2007. Regulamenta o Fundo de Manutenção e Desenvolvimento da Educação Básica e de Valorização dos Profissionais da Educação FUNDEB, de que trata o art. 60 do Ato das Disposições Constitucionais Transitórias; altera a Lei $\mathrm{n}^{0} 10.195$, de 14 de fevereiro de 2001; revoga dispositivos das Leis $\mathrm{n}^{\text {os }} 9.424$, de 24 de dezembro de 1996, 10.880, de 9 de junho de 2004, e 10.845, de 5 de março de 2004; e dá outras providências. Disponível em: www.planalto.gov.br. Acesso em: ago. 2013.

CALLEGARI, c. (Org.). Fundeb: financiamento da educação pública no estado de São Paulo. São Paulo: Ground: APEOESP, 2008.

CRUZ, Rosana Evangelista da. O Financiamento da Educação Pública no Brasil. In: COUTINHO, Adelaide Ferreira. (Org.). Reflexões sobre Políticas Educacionais no Brasil: consensos e dissensos sobre a educação pública. São Luís: EDUFMA, 2009, p. 88-108.

DAVIS, Nicholas. FUNDEB: A redenção da educação básica? Educ. Soc., Campinas, vol. 27, n. 96 - Especial, p. 753-774, out. 2006.

PINTO, J. M. de R.; ADRIÃO, T. Noções gerais sobre financiamento da educação no Brasil. EccoS - Revista Científica, São Paulo, vol. 8, n. 1, p. 23-46, jan./jun. 2006.

RAMOS, Regina Celia; DI GIORGI, Cristiano Amaral. Do Fundef ao Fundeb: avaliando o passado para pensar o futuro: um estudo de caso no município de Pirapozinho-SP. Ensaio: Avaliação e Políticas Públicas em Educação, 2011, vol.19, n.72. 
SENA, P. A União e a aplicação dos recursos vinculados à manutenção e ao desenvolvimento do ensino. Revista Brasileira Est. Pedag., Brasília, v. 83, n. 203/204/205, p. 7-22, jan./dez. 2002.

WINCKLER, C. R.; SANTAGADA, S. O Fundeb: novos horizontes para a educação básica? Indicadores Econômicos FEE, v. 35, p. 1-12, 2007. 